\title{
Predictors of successful percutaneous coronary intervention in chronic total coronary occlusions
}

\author{
Ahmet Oytun Baykan ${ }^{1}$, Mustafa Gür$^{2}$, Armağan Acele ${ }^{1}$, Taner Şeker ${ }^{1}$, Alaa Quisi' ${ }^{1}$, Ali Kıvrak ${ }^{1}$, Arafat Yıldırım¹, \\ Hakan Uçar ${ }^{1}$, Selahattin Akyol ${ }^{1}$, Murat Çaylı ${ }^{3}$ \\ ${ }^{1}$ Department of Cardiology, Adana Numune Training and Research Hospital, Adana, Turkey \\ ${ }^{2}$ Department of Cardiology, School of Medicine, Kafkas University, Kars, Turkey \\ ${ }^{3}$ Department of Cardiology, School of Medicine, Dicle University, Diyarbakır, Turkey
}

Adv Interv Cardiol 2016; 12, 1 (43): 17-24

DOI: $10.5114 /$ pwki.2016.56945

\begin{abstract}
Introduction: Percutaneous coronary intervention ( $\mathrm{PCl}$ ) of chronic total coronary occlusions (CTOs) is one of the most challenging procedures of interventional cardiology and is associated with increased risk of significant complications. However, debate continues in regard to which factors adversely influence the success rate of $\mathrm{PCl}$ and whether the benefits of revascularization of СTO outweigh the risks and challenges.

Aim: To analyze the relationship between lesion characteristics and overall success rates as well as in-hospital outcomes after PCl for CTO.

Material and methods: We retrospectively examined the procedural outcomes of 173 consecutive native coronary artery CTO PCls performed from February 2012 to March 2013 (78\% men; mean age: $60.3 \pm 12.1$ years).

Results: The CTO target vessel was the right coronary artery (53.8\%), circumflex (10.4\%) and left anterior descending artery (35.8\%), respectively. The retrograde approach was used in $13.9 \%$ of all procedures. Successful revascularization was achieved in $83.2 \%$ of patients. Major complications occurred in $13.3 \%$ of patients. In multivariate analysis, bridge collaterals, severe calcification and tortuosity as well as tandem occlusions were independent predictors of procedural failure, whereas existence of micro-channels was the only predictor of procedural success.

Conclusions: Revascularization of coronary CTOs may be performed with high success and low major complication rates. Bridge collaterals, severe calcification and tortuosity, tandem/multiple occlusions and micro-channels were independent predictors of successful CTO revascularization.
\end{abstract}

Key words: revascularization, coronary chronic total occlusion, lesion characteristics, procedural success.

\section{Introduction}

The incidence of coronary chronic total occlusions (CTO) among patients with a clinical indication for diagnostic coronary angiography is nearly $20 \%$ [1]. Nonetheless, according to the available data, percutaneous coronary intervention $(\mathrm{PCI})$ rates for CTOs are as low as $10-15 \%$ and most of these patients are treated with medical therapy or coronary artery bypass grafting surgery (CABG) [2]. Successful recanalization of CTOs can reduce the ischemic burden and symptoms as well as electrical instability, improves exercise capacity and tends to show a positive effect on left ventricular (LV) remodeling and ejection fraction (LVEF) [3, 4]. Percutaneous coronary intervention for CTO is considered to be one of the most challenging procedures of interventional cardiology, and in the earlier studies, successful recanalization rates of CTO ranged from $51 \%$ to $74 \%$ [5]. However, with improved operator experience and the development of novel equipment and techniques, procedural success rates have been increased, which brings an increasing number of CTO into a treatable category [6, 7]. In several previous studies, it has been reported that the appropriate use of both antegrade and retrograde approaches has noticeably improved the overall success without increasing the rate of major complications [8]. Moreover, large studies investigating patients with CTO in different clinical settings have demonstrated short- and long-term survival advantages in patients with successfully revascularized 
when compared with failed procedures and have tried to determine clinical and procedural predictors of the success and outcome [9]. However, debate continues in regard to which factors adversely influence the success rate of $\mathrm{PCl}$ and whether the benefits of revascularization of CTO outweigh the risks and challenges.

\section{Aim}

The purpose of the present study was to analyze the relationship between lesion characteristics and overall success rates as well as in-hospital outcomes after $\mathrm{PCl}$ for CTO.

\section{Material and methods}

\section{Study design and patient population}

During the period from February 2012 to March 2013, 173 consecutive patients ( $78 \%$ men; mean age $60.3 \pm 12.1$ years) who underwent $\mathrm{PCI}$ for CTO of a native coronary artery were included in this retrospective study. The indication for coronary angiography in all patients and subsequent $\mathrm{PCl}$ for CTO was the presence of angina and the demonstration of viable myocardium or silent reversible ischemia in the territory of the occluded artery on myocardial perfusion imaging. Patients with recent myocardial infarction (MI) or unstable hemodynamics, total occlusion of bypass grafts and stents were excluded from the study. After taking detailed medical history and complete physical examination, each participant was questioned for major cardiovascular risk factors such as age, sex, diabetes mellitus (DM), smoking status and hypertension (HT). Estimated glomerular filtration rate (eGFR), calculated by the simplified MDRD equation, was used for the assessment of renal functions [10]. The study was conducted according to the recommendations set forth by the Declaration of Helsinki on Biomedical Research Involving Human Subjects. The Institutional Ethics Committee approved the study protocol and each participant provided written informed consent.

Coronary CTOs were defined as angiographic evidence of a total occlusion with Thrombolysis In Myocardial Infarction (TIMI) grade 0 or 1 and estimated duration of at least 3 months [11]. Estimation of occlusion duration was based on the first onset of angina pectoris, a history of myocardial infarction in the target vessel territory, or comparison with a previous angiogram. Technical success was defined as successful CTO recanalization with achievement of $<30 \%$ residual diameter stenosis within the treated segment and restoration of TIMI grade-3 antegrade flow [12]. In-hospital major adverse cardiac events included any of the following adverse events before hospital discharge: myocardial infarction (both Q-wave and non-Q-wave), recurrent angina requiring urgent repeat target vessel revascularization with $\mathrm{PCl}$ or coronary bypass surgery, tamponade requiring pericardiocentesis or surgery, or death from any cause.

\section{Definitions and lesion characteristics}

Multi-vessel disease was defined as stenosis of $\geq 70 \%$ in more than one major coronary artery. Severe tortuosity was defined as there being one or more bends of $90^{\circ}$ or more, or three or more bends of $45-90^{\circ}$ proximal of the diseased segment. Presence of calcification was assigned to two categories according to severity. Moderate-severe calcification was accepted as multiple persisting opacifications of the coronary wall visible in at least one projection surrounding the complete lumen of the coronary artery at the site of the lesion, or mild calcification if it did not. The angiographic structure of the occlusion was defined as tapered stump (funnel shape narrowing of the proximal cap with or without a clear microchannel), blunt stump (abrupt occlusion with no microchannel), or stumpless (proximal cap could not be angiographically defined). Intracoronary microchannels at the site of the occlusion were considered to be bridging collateral vessels that established the chronicity of the occlusion. Contralateral injection, performed when retrograde collateral flow was present, was defined as simultaneous dye injection to show the distal portion of the vessel after the occlusion site (filled via collateral vessels) and to estimate the length of the occlusion.

Coronary lesions leading to a diameter stenosis of $\geq 50 \%$ in vessels of $\geq 1.5 \mathrm{~mm}$ were scored separately and added together to provide the cumulative SYNTAX score, which was prospectively calculated using the SYNTAX score algorithm on the baseline diagnostic angiogram [13]. Moreover, the Multicenter Chronic Total Occlusion Registry of Japan (J-CTO) scoring system was calculated using parameters of lesion complexity such as prior failed attempt, angiographic evidence of heavy calcification, bending within the occluded segment, blunt proximal stump, and occlusion length > $20 \mathrm{~mm}$ [14]. Two experienced interventional cardiologists, who were blinded to the clinical characteristics and laboratory results of the patients, examined coronary angiograms, collateral grading, J-CTO score and SYNTAX score. The opinion of a third analyst was obtained and the final judgment was made by consensus in cases of disagreement.

\section{Interventional procedure}

Aspirin and loading dose of clopidogrel (600 mg) were given to all patients before the procedure, and dual antiplatelet therapy was prescribed for 12 months after discharge. A bolus of 80-100 U/kg unfractionated heparin was given before the procedure and followed by intravenous infusion to achieve an activated clotting time $>250 \mathrm{~s}$ during the procedure. Selection of the wiring techniques and the guidewires was based on the operator's discretion and the patient's coronary anatomy. The antegrade approach was routinely used, and, depending on procedural progress, different strategies and the use of stiffer wires were considered. Retrograde wiring was 
defined as a technique that involves manipulating and advancing the guidewire through microcatheters via collaterals into the CTO retrogradely to reach the proximal true lumen and achieve successful recanalization. The distal wire position was confirmed to be in the true lumen by either a coronary angiogram or intravascular ultrasound examination.

Two experienced operators in our institution performed the CTO intervention procedures. The experienced operators met the criteria of "CTO operators" who had specific proctored experience of more than 100 CTOs [15].

\section{Statistical analysis}

The analyses were performed using the SPSS software (Statistical Package for the Social Sciences, Version 20.0, SPSS Inc., Chicago, IL, USA). Continuous variables were expressed as mean \pm SD and categorical variables were expressed as percentages. Analysis of normality was performed with the Kolmogorov-Smirnov test. Comparison of categorical variables between the groups was performed using the chi-square $\left(\chi^{2}\right)$ test. Comparisons of continuous variables between the two groups were performed using the independent samples $t$-test. Multivariate, stepwise backward conditional logistic regression analysis was used to determine the independent predictors of successful intervention. All significant parameters in the univariate analysis were selected in the multivariate model. A two-tailed $p$-value of less than 0.05 was considered as significant.

\section{Results}

A total of 173 patients (135 men; mean age: 60.3 \pm 12.1 years) underwent $\mathrm{PCl}$ for CTO. There were 144 patients (113 men; mean age: $60.6 \pm 12.3$ years) in the CTO success group and 29 patients ( 22 men; mean age: $58.8 \pm 11.4$ years) in the CTO failure group. Demographic, clinical and laboratory characteristics of the study population are shown in Table I. More than 1/5 (24.9\%) had a family history of coronary artery disease (CAD), $21.4 \%$ had diabetes, $60.7 \%$ had hypertension and $35.3 \%$

Table I. Demographic, clinical and laboratory characteristics of patients

\begin{tabular}{|c|c|c|c|c|}
\hline Parameter & $\begin{array}{c}\text { Patients } \\
(n=173) \\
\end{array}$ & $\begin{array}{c}\text { Technical success } \\
(n=144) \\
\end{array}$ & $\begin{array}{l}\text { Technical failure } \\
(n=29)\end{array}$ & Value of $p$ \\
\hline \multicolumn{5}{|c|}{ Demographic and clinical findings: } \\
\hline Age [years] & $60.3 \pm 12.1$ & $60.6 \pm 12.3$ & $58.8 \pm 11.4$ & 0.473 \\
\hline Gender (male) & $135(78)$ & $113(78.5)$ & $22(75.9)$ & 0.462 \\
\hline Diabetes & $37(21.4)$ & $30(20.8)$ & $7(24.1)$ & 0.429 \\
\hline Hypertension & $105(60.7)$ & $87(60.4)$ & $18(62.1)$ & 0.521 \\
\hline Hyperlipidemia & $61(35.3)$ & $52(36.1)$ & $9(31.0)$ & 0.384 \\
\hline Family history & $43(24.9)$ & $34(23.6)$ & $9(31.0)$ & 0.266 \\
\hline Smoking & $106(61.3)$ & 89 (61.8) & $17(58.6)$ & 0.451 \\
\hline$\overline{C A B G}$ & $22(12.7)$ & $20(13.9)$ & $2(6.9)$ & 0.243 \\
\hline Previous PCl & $42(24.3)$ & $37(25.7)$ & $5(17.2)$ & 0.237 \\
\hline Renal failure & $14(8.1)$ & $11(7.6)$ & $3(10.3)$ & 0.427 \\
\hline \multicolumn{5}{|l|}{ Laboratory findings: } \\
\hline Total cholesterol [mg/dl] & $193.2 \pm 44.3$ & $193.9 \pm 45.6$ & $189.7 \pm 37.6$ & 0.643 \\
\hline Triglyceride [mg/dl] & $170.1 \pm 93.6$ & $166.9 \pm 87.9$ & $186.0 \pm 118.1$ & 0.318 \\
\hline HDL cholesterol [mg/dl] & $36.3 \pm 8.4$ & $36.7 \pm 8.7$ & $34.0 \pm 6.1$ & 0.110 \\
\hline LDL cholesterol [mg/dl] & $126.0 \pm 40.9$ & $127.4 \pm 41.9$ & $119.3 \pm 35.2$ & 0.335 \\
\hline Serum creatinine $[\mathrm{mg} / \mathrm{dl}]$ & $1.07 \pm 0.97$ & $0.97 \pm 0.34$ & $1.57 \pm 2.20$ & 0.002 \\
\hline eGFR $\left[\mathrm{ml} / \mathrm{min} / 1.73 \mathrm{~m}^{2}\right]$ & $88.6 \pm 32.8$ & $88.8 \pm 29.9$ & $85.4 \pm 47.6$ & 0.622 \\
\hline Uric acid [mg/dl] & $6.05 \pm 1.86$ & $6.04 \pm 1.88$ & $6.14 \pm 1.80$ & 0.782 \\
\hline Hemoglobin [mg/dl] & $12.7 \pm 1.7$ & $12.7 \pm 1.6$ & $12.3 \pm 1.9$ & 0.211 \\
\hline Platelet count, $\times 10^{9} / l$ & $240.8 \pm 79.4$ & $242.6 \pm 75.7$ & $231.9 \pm 96.4$ & 0.512 \\
\hline
\end{tabular}

Data are presented as the number (\%) of patients or mean value $\pm S D$. HDL - High-density lipoprotein, LDL-low-density lipoprotein, CABG - coronary artery bypass graft, $\mathrm{PCl}$ - percutaneous coronary intervention, eGFR - estimated glomerular filtration rate. 
had a history of hyperlipidemia. The clinical and laboratory characteristics were similar between the groups, including eGFR, except for serum creatinine, which was found to be higher in the CTO failure group $(p=0.002)$.

\section{Angiographic and procedural findings}

The majority of patients had multivessel disease, and the right coronary artery (RCA) was the target vessel in most of the patients (53.8\%). Nine percent of patients had at least 1 previous failed attempt at CTO recanalization. Most PCls (76\%) were performed using an antegrade approach. The overall technical success rate was $83.2 \%$. The average stent length was $60.5 \pm 26.2 \mathrm{~mm}$, and drug-eluting stents (DES) were used in all of the patients. Contralateral injection was performed in 154 (89\%) patients (Table II).

The incidences of severe calcification, severe tortuosity, absence of tapered stump, existence of bridging collaterals, J-CTO score and tandem occlusions were found to be higher in the CTO failed group ( $p<0.05$, for all), whereas existence of micro-channels and large vessel diameter (>3 mm) were more frequent in the successful revascularization group ( $p<0.05$, for all) (Table II). In multivariate analysis, bridge collaterals (OR: $0.114,95 \% \mathrm{Cl}$ : $0.035-0.374, p<0.001$ ), severe calcification (OR: 0.206, $95 \% \mathrm{Cl}: 0.058-0.738, p=0.015)$ and tortuosity (OR: $0.085,95 \% \mathrm{Cl}: 0.013-0.579, p=0.012)$ as well as tandem occlusions (OR: $7.075,95 \% \mathrm{Cl}: 1.364-36.702, p=0.020$ ) were independently associated with higher technical failure rates. On the other hand, existence of micro-channels (OR: $0.160,95 \% \mathrm{Cl}: 0.040-0.640, p=0.010$ ) was the only independent predictor of technical success (Table III).

A procedural complication occurred in 23 (13.3\%) patients (Table IV). One patient died due to intracranial bleeding. Six patients had coronary artery perforation and one of them caused cardiac tamponade that required pericardiocentesis. Sixteen patients had coronary dissection, all of which were treated successfully with stent implantation.

\section{Discussion}

The results of the present study suggest that the most powerful predictors of technical failure are bridge collaterals, tandem occlusions, severe calcification and tortuosity. On the other hand, existence of micro-channels is the only predictor of technical success. Moreover, we observed that revascularization is not only an effective but also a safe therapeutic option in adequately selected CTO patients, with a high success rate and low prevalence of complications.

Chronic total occlusive lesions are characterized by heavy atherosclerotic burden, uncertain course of the vessel at the site of occlusion, and longer length of lesions within the artery, which cause a lower success rate in revascularization than that of non-CTOs [16]. The CTOs are the most complex and challenging coronary lesions for percutaneous revascularization. In several previous studies, the procedural success rates were reported between $58.9 \%$ and $75.2 \%[4,17]$. Recently, the reported success rate of CTO-PCI has reached $>80 \%$ owing to the use of new sophisticated techniques and development of specialized devices $[18,19]$. The overall technical success rate of the present study is $83.2 \%$ and is similar to those reported in recent large United States and European CTO $\mathrm{PCl}$ registries (85.5\% to $87.5 \%$ ) [20]. This is likely because of application of novel crossing strategies (including the retrograde approach and dissection or reentry techniques), novel equipment (microcatheters, guidewires, over the wire balloons (OTWs) and DES) and increasing operator experience [21, 22].

Currently, the most utilized CTO crossing strategies are antegrade wire escalation, antegrade dissection/ re-entry, and the retrograde approach [23]. The retrograde approach, introducing a guidewire through a collateral vessel to reach a coronary segment distal to the occlusion, has been reported to significantly increase the procedural success rates of $\mathrm{CTO} P C I[24,25]$. In the present study, retrograde approach was used in $13.9 \%$ of cases. In the J-CTO registry, procedural success rate was $88.6 \%$ and retrograde approach was used in $25 \%$ of the cases in 528 CTO lesions [26]. Therefore, when compared the success rates of previous CTO $\mathrm{PCl}$ studies in which the retrograde approach was not used, we may claim that the retrograde approach improves success especially in complex CTO PCls.

The morphology of chronic total occlusive plaque is composed of dense, loose and cellular fibrous tissue, as well as calcium, foam cells, and lymphocyte infiltration without foam cells [27]. Therefore, this plaque morphology entail difficulties in crossing a total occlusion with a guidewire, which is the most common reason for failure of CTO revascularization [28]. Thus, it is important to evaluate the probability of success before attempting percutaneous revascularization in CTOs. Although several studies were designed to investigate the influential factors, debate continues in regard to the impact of various clinical and angiographic factors on success, failure of $\mathrm{PCl}$ and long-term clinical outcome [29]. It has been reported that several angiographic factors such as absence of tapered stump structure, presence of bridging collateral vessels, and the presence of a side branch at the occlusion site are predictors of technical failure $[14,30]$. Severe tortuosity and moderate-to-severe calcification have also been demonstrated to be predictors of technical failure [31]. Moreover, multivessel disease, lesion lengths >15 mm and subsequent CABG are considered to be associated with less CTO PCI success [29, 32]. Our results support some of the conclusions mentioned above but not others. For instance, absence of tapered stump, multivessel disease, and lesion length 
Table II. Angiographic characteristics of study population

\begin{tabular}{|c|c|c|c|c|}
\hline Parameter & $\begin{array}{l}\text { Patients } \\
(n=173) \\
\end{array}$ & $\begin{array}{c}\text { Technical success } \\
(n=144)\end{array}$ & $\begin{array}{l}\text { Technical failure } \\
(n=29)\end{array}$ & Value of $p$ \\
\hline Target vessel: & - & - & - & 0.170 \\
\hline$\overline{L A D}$ & $62(35.8)$ & $52(36.1)$ & $10(34.5)$ & \\
\hline$C x$ & $18(10.4)$ & $14(9.7)$ & $4(13.7)$ & \\
\hline RCA & $93(53.8)$ & $78(54.2)$ & $15(51.7)$ & \\
\hline Multivessel disease: & - & - & - & 0.476 \\
\hline IVD & $20(11.6)$ & $15(10.4)$ & $5(17.2)$ & \\
\hline $2 \mathrm{VD}$ & $58(33.5)$ & $54(37.5)$ & $4(13.8)$ & \\
\hline $3 \mathrm{VD}$ & $95(54.9)$ & $75(52.1)$ & $20(69)$ & \\
\hline Previous failed attempt for CTO PCI & $16(9.2)$ & $13(9)$ & $3(10.3)$ & 0.524 \\
\hline Syntax score & $22.5 \pm 6.9$ & $22.4 \pm 6.9$ & $22.7 \pm 6.9$ & 0.830 \\
\hline Syntax score $>33$ & $20(11.6)$ & $17(11.8)$ & $3(10.3)$ & 0.559 \\
\hline J-CTO score & $1.9 \pm 0.85$ & $1.9 \pm 0.84$ & $2.3 \pm 0.81$ & 0.006 \\
\hline Average stent length & $60.5 \pm 26.2$ & - & - & - \\
\hline DES & $173(100)$ & - & - & - \\
\hline Retrograde approach & $24(13.9)$ & $18(12.5)$ & $6(20.7)$ & 0.189 \\
\hline Side branch & $71(41.0)$ & $57(39.6)$ & $14(48.3)$ & 0.253 \\
\hline Absence of tapered stump & $80(46.2)$ & $62(43.1)$ & $18(62.1)$ & 0.048 \\
\hline Severe tortuosity & $18(10.4)$ & $11(7.6)$ & $7(24.1)$ & 0.015 \\
\hline Severe calcification & $57(32.9)$ & $38(26.4)$ & $19(65.5)$ & $<0.001$ \\
\hline Lesion length > $20 \mathrm{~mm}$ & $156(90.2)$ & $128(88.9)$ & $28(96.6)$ & 0.181 \\
\hline Vessel diameter $>3 \mathrm{~mm}$ & $84(48.6)$ & $78(54.2)$ & $6(20.7)$ & 0.001 \\
\hline Bridging collaterals & $38(22)$ & $20(13.9)$ & $18(62.1)$ & $<0.001$ \\
\hline Micro-channels & $85(49.1)$ & $80(55.6)$ & $5(17.2)$ & $<0.001$ \\
\hline Tandem occlusions & $59(34.1)$ & $55(38.2)$ & $4(13.8)$ & 0.008 \\
\hline Ostial localization & $12(6.9)$ & $8(5.6)$ & $4(13.8)$ & 0.120 \\
\hline Poor guiding catheter support & $7(4)$ & 0 & $7(24.1)$ & $<0.001$ \\
\hline Contralateral injection & $154(89)$ & $127(88.2)$ & $27(93.1)$ & 0.347 \\
\hline Guiding catheter type: & - & - & - & 0.209 \\
\hline Judkins & $141(81.5)$ & $115(79.9)$ & $26(89.6)$ & \\
\hline Extra-support & $30(17.3)$ & $27(18.8)$ & $3(10.3)$ & \\
\hline Amplatz & $2(1.2)$ & $2(1.4)$ & 0 & \\
\hline Guiding catheter size: & - & - & - & 0.629 \\
\hline $6 \mathrm{Fr}$ & $73(42.2)$ & $59(41)$ & $14(48.3)$ & \\
\hline $7 \mathrm{Fr}$ & $73(42.2)$ & $61(42.4)$ & $12(41.4)$ & \\
\hline $8 \mathrm{Fr}$ & $27(15.6)$ & $24(16.7)$ & $3(10.3)$ & \\
\hline Guidewires: & - & - & - & 0.730 \\
\hline Fielder FC & $2(1.2)$ & $1(0.7)$ & $1(3.4)$ & \\
\hline Fielder XT & $55(31.8)$ & $46(31.9)$ & $9(31)$ & \\
\hline PT2 MS & $74(42.8)$ & $64(44.4)$ & $10(34.5)$ & \\
\hline Pilot 150-200 & 20 (11.6) & $17(11.8)$ & $3(10.3)$ & \\
\hline Miracle series & $13(7.5)$ & $11(7.6)$ & $2(6.9)$ & \\
\hline Conquest & $63(36.4)$ & $53(36.8)$ & $10(34.5)$ & \\
\hline PT-Graphix & $35(20.2)$ & $28(19.4)$ & $7(24.1)$ & \\
\hline Cross-IT & $2(1.2)$ & $1(0.7)$ & $1(3.4)$ & \\
\hline Penetration technique: & - & - & - & 0.478 \\
\hline Deep intubation & 19 (11.0) & $14(9.7)$ & $5(17.2)$ & \\
\hline Anchor balloon & 25 (14.5) & 20 (13.9) & $5(17.2)$ & \\
\hline Parallel wire & $4(2.3)$ & $4(2.8)$ & 0 & \\
\hline Jailed anchor & $6(3.5)$ & $6(4.2)$ & 0 & \\
\hline Supportive equipment: & & - & - & 0.091 \\
\hline Over the wire balloon & $112(64.7)$ & $95(66.0)$ & $17(58.6)$ & \\
\hline Micro-catheters & $30(17.3)$ & $22(15.3)$ & $8(27.6)$ & \\
\hline
\end{tabular}

Data are presented as the number (\%) of patients or mean value $\pm S D$. LAD - Left anterior descending artery, CX - circumflex artery, RCA - right coronary artery, $V D$ - vessel disease, CTO - coronary total occlusion, $P C I$ - percutaneous coronary intervention, DES - drug-eluting stent. 
Table III. Independent predictors for failure of CTO revascularization

\begin{tabular}{lccc} 
Variables & Odds ratio & $95 \% \mathrm{Cl}$ & Value of $p$ \\
\hline Bridge collaterals & 0.114 & $0.035-0.374$ & $<.001$ \\
\hline Severe calcification & 0.206 & $0.058-0.738$ & 0.015 \\
\hline Severe tortuosity & 0.085 & $0.013-0.579$ & 0.012 \\
\hline Tandem occlusions & 7.075 & $1.364-36.702$ & 0.020 \\
\hline Micro-channels & 0.160 & $0.040-0.640$ & 0.010 \\
\hline Vessel diameter $>3 \mathrm{~mm}$ & 0.550 & $0.152-1.995$ & 0.363 \\
\hline J-CTO score & 1.327 & $0.318-5.538$ & 0.698 \\
\hline Absence of tapered stump & 0.451 & $0.129-1.572$ & 0.211 \\
\hline Serum creatinine & 1.693 & $0.560-5.118$ & 0.351
\end{tabular}

Cl-Confidence interval, CTO - chronic total occlusion.

Table IV. Complications and in-hospital clinical outcomes

\begin{tabular}{lccc} 
Clinical outcomes & $\begin{array}{c}\text { Patients } \\
(n=173)\end{array}$ & $\begin{array}{c}\text { Technical success } \\
(n=144)\end{array}$ & $\begin{array}{c}\text { Technical failure } \\
(n=29)\end{array}$ \\
\hline $\begin{array}{l}\text { Procedural complications: } \\
\text { Coronary dissection }\end{array}$ & $16(9.2)$ & $14(9.7)$ & $2(6.9)$ \\
\hline Coronary perforation & $6(3.5)$ & $5(3.5)$ & $1(3.4)$ \\
\hline Tamponade & $1(0.6)$ & $1(0.7)$ & 0 \\
\hline Death & $1(0.6)$ & $1(0.7)$ & 0.678 \\
\hline Myocardial infarction: & 0 & 0 & 0 \\
\hline $\begin{array}{l}\text { Q wave } \\
\text { Non-Q wave }\end{array}$ & $4(2.3)$ & $3(2.1)$ & $1(3.4)$ \\
\hline Urgent revascularization & 0 & 0 & 0
\end{tabular}

Data are presented as the number and percentage of patients.

$>30 \mathrm{~mm}$, identified as negative predictors of success in previous studies, had no predictive value in our study. This conflict might be elucidated by diversity in definitions and durations of chronic occlusion and excluding some important variables such as angiographic structure in previous studies. Moreover, this incongruity might be a consequence of contemporary devices, techniques, and improved operator experience, which reduces the negative impact of lesion length and stump structure of lesion on technical success.

In the present study, the incidence of major adverse events such as death, urgent revascularization, stroke, and $\mathrm{MI}$ was similar to previously published large series, as a result of concomitant improvement in the rate of angiographic success [33]. The incidence of coronary dissection (9.2\%), which occurs mainly due to subintimal advancement of the guidewires, and coronary perforation (3.5\%) in our study agrees with the series reported by Mehran et al. (9.4\% and 3.5\%, respectively) [34]. Another finding of our study is that when coronary perforation occurred, it only caused tamponade in $1(0.6 \%)$ patient. Therefore, our results suggest that although coronary perforation is one of the most worrying complications of CTO PCl, when only the guidewire enters the pericardial space without introducing a balloon or microcatheter, its possibility to cause a tamponade is very low [35].

In the light of our findings, several factors might have influenced the success rate of $\mathrm{CTO} \mathrm{PCl}$ in the present study. First of all, although eGFR was similar between the technical success and failure groups, the serum creatinine level was significantly higher in the failure group. In addition, we observed that poor guiding catheter support was more frequently found in the failure group. However, guiding catheters with strong back-up were less frequently used in the failure group. Therefore, limitation of the use of contrast and preferential use of poor back-up guiding catheters by the operators might affect procedural success. 
Several limitations of the present study should be mentioned. First, our study is limited by its retrospective and observational design. Second, the number of patients in our failure group was relatively small and was 4 times lower than the number in the success group, which may influence the power of our study and our findings. Likewise, such a problem has been observed in previous studies, which reported success rates of CTO PCI between $60 \%$ and $88 \%$. However, in the present study, the frequencies of most variables that were not significantly different between the groups were very similar, and it seems that the results would not change if the sample size were larger. Third, this was a single center experience without a multicenter registry analysis. Fourth, systematic evaluation for certain complications, such as vascular entrance complications, contrast nephropathy, and radiation skin injury, was not performed. Moreover, long-term clinical follow-up was not obtained.

\section{Conclusions}

According to the results of our study, we may suggest that the most powerful predictors of technical failure are bridge collaterals, tandem occlusions, severe calcification and tortuosity. On the other hand, presence of micro-channels is the only predictor of technical success. In addition, depending on the novel equipment, contemporary techniques, and careful selection of patients, as well as operator expertise, percutaneous revascularization may be not only an effective but also a safe therapeutic option for CTO patients.

\section{Conflict of interest}

The authors declare no conflicts of interest.

\section{References}

1. Grantham JA, Marso SP, Spertus J, et al. Chronic total occlusion angioplasty in the United States. JACC Cardiovasc Interv 2009; 2: 479-86

2. Hoye A, van Domburg RT, Sonnenschein K, et al. Percutaneous coronary intervention for chronic total occlusions: the Thoraxcenter experience 1992-2002. Eur Heart J 2005; 26: 2630-6.

3. Tamburino C, Capranzano P, Capodanno D, et al. Percutaneous recanalization of chronic total occlusions: wherein lies the body of proof? Am Heart J 2013; 165: 133-42.

4. Olivari Z, Rubartelli P, Piscione F, et al. Immediate results and one-year clinical outcome after percutaneous coronary interventions in chronic total occlusions: data from a multicenter, prospective, observational study (TOAST-GISE). J Am Coll Cardiol 2003; 41: 1672-8.

5. Prasad A, Rihal CS, Lennon RJ, et al. Trends in outcomes after percutaneous coronary intervention for chronic total occlusions: a 25-year experience from the Mayo Clinic. J Am Coll Cardiol 2007; 49: 1611-8.

6. Michael TT, Karmpaliotis D, Brilakis ES, et al. Procedural outcomes of revascularization of chronic total occlusion of native coronary arteries (from a multicenter United States registry). Am J Cardiol 2013; 112: 488-92.
7. Tasic M, Sreckovic MJ, Jagic N, et al. Knuckle technique guided by intravascular ultrasound for in-stent restenosis occlusion treatment. Postep Kardiol Inter 2015; 11: 58-61.

8. Rathore S, Katoh O, Matsuo H, et al. Retrograde percutaneous recanalization of chronic total occlusion of the coronary arteries: procedural outcomes and predictors of success in contemporary practice. Circ Cardiovasc Interv 2009; 2: 124-32.

9. Jones DA, Weerackody R, Rathod K, et al. Successful recanalization of chronic total occlusions is associated with improved long-term survival. JACC Cardiovasc Interv 2012; 5: 380-8.

10. Levey AS, Bosch JP, Lewis JB, et al. A more accurate method to estimate glomerular filtration rate from serum creatinine: a new prediction equation. Modification of Diet in Renal Disease Study Group. Ann Intern Med 1999; 130: 461-70.

11. Sianos G, Werner GS, Galassi AR, et al. Recanalisation of chronic total coronary occlusions: 2012 consensus document from the EuroCTO club. Eurolntervention 2012; 8: 139-45.

12. Thompson CA, Jayne JE, Robb JF, et al. Retrograde techniques and the impact of operator volume on percutaneous intervention for coronary chronic total occlusions an early U.S. experience. JACC Cardiovasc Interv 2009; 2: 834-42.

13. Sianos G, Morel MA, Kappetein AP, et al. The SYNTAX Score: an angiographic tool grading the complexity of coronary artery disease. Eurolntervention 2005; 1: 219-27.

14. Morino $\mathrm{Y}$, Abe $M$, Morimoto T, et al. Predicting successful guidewire crossing through chronic total occlusion of native coronary lesions within 30 minutes: the J-CTO (Multicenter CTO Registry in Japan) score as a difficulty grading and time assessment tool. JACC Cardiovasc Interv 2011; 4: 213-21.

15. Di Mario C, Werner GS, Sianos G, et al. European perspective in the recanalisation of chronic total occlusions (CTO): consensus document from the EuroCTO Club. Eurolntervention 2007; 3: 30-43.

16. Cetin M, Karaman K, Zencir C, et al. Results of percutaneous coronary intervention for chronic total occlusions of coronary arteries: a single center report. Turk Kardiyol Dern Ars 2013; 41: 505-12.

17. Suero JA, Marso SP, Jones PG, et al. Procedural outcomes and long-term survival among patients undergoing percutaneous coronary intervention of a chronic total occlusion in native coronary arteries: a 20-year experience. J Am Coll Cardiol 2001; 38: 409-14.

18. Sianos G, Barlis P, Di Mario C, et al. European experience with the retrograde approach for the recanalisation of coronary artery chronic total occlusions. A report on behalf of the euroCTO club. Eurolntervention 2008; 4: 84-92.

19. Bryniarski KL, Zabojszcz M, Debski G, et al. What Polish interventional cardiologists know about indications and qualification for recanalisation of chronic total coronary artery occlusions? Kardiol Pol 2015; 73: 722-9.

20. Galassi AR, Tomasello SD, Reifart N, et al. In-hospital outcomes of percutaneous coronary intervention in patients with chronic total occlusion: insights from the ERCTO (European Registry of Chronic Total Occlusion) registry. Eurolntervention 2011; 7: 472-9.

21. Bryniarski L, Kusak P, Surowiec S, et al. Dedicated devices and techniques - a cornerstone in recanalisation of chronic total occlusions of coronary arteries. Postep Kardiol Inter 2014; 10 : 213-5.

22. Bryniarski KL, Zabojszcz M, Debski G, et al. Knowledge of chronic total occlusion among Polish interventional cardiologists. Postep Kardiol Inter 2015; 11: 89-94. 
23. Brilakis ES, Grantham JA, Rinfret S, et al. A percutaneous treatment algorithm for crossing coronary chronic total occlusions. JACC Cardiovasc Interv 2012; 5: 367-79.

24. Brilakis ES, Grantham JA, Thompson CA, et al. The retrograde approach to coronary artery chronic total occlusions: a practical approach. Catheter Cardiovasc Interv 2012; 79: 3-19.

25. Karmpaliotis D, Michael TT, Brilakis ES, et al. Retrograde coronary chronic total occlusion revascularization: procedural and in-hospital outcomes from a multicenter registry in the United States. JACC Cardiovasc Interv 2012; 5: 1273-9.

26. Morino Y, Kimura T, Hayashi Y, et al. In-hospital outcomes of contemporary percutaneous coronary intervention in patients with chronic total occlusion insights from the J-CTO Registry (Multicenter CTO Registry in Japan). JACC Cardiovasc Interv 2010; 3: 143-51.

27. Kragel AH, Reddy SG, Wittes JT, et al. Morphometric analysis of the composition of atherosclerotic plaques in the four major epicardial coronary arteries in acute myocardial infarction and in sudden coronary death. Circulation 1989; 80: 1747-56.

28. Kinoshita I, Katoh O, Nariyama J, et al. Coronary angioplasty of chronic total occlusions with bridging collateral vessels: immediate and follow-up outcome from a large single-center experience. J Am Coll Cardiol 1995; 26: 409-15.

29. Rathore S, Matsuo H, Terashima M, et al. Procedural and in-hospital outcomes after percutaneous coronary intervention for chronic total occlusions of coronary arteries 2002 to 2008: impact of novel guidewire techniques. JACC Cardiovasc Interv 2009; 2: 489-97.

30. Bufe A, Haltern G, Dinh W, et al. Recanalisation of coronary chronic total occlusions with new techniques including the retrograde approach via collaterals. Neth Heart J 2011; 19: 162-7.

31. Garcia-Garcia HM, Brugaletta S, van Mieghem CA, et al. CRosser As First choice for crossing Totally occluded coronary arteries (CRAFT Registry): focus on conventional angiography and computed tomography angiography predictors of success. Eurolntervention 2011; 7: 480-6.

32. Yamamoto E, Natsuaki M, Morimoto T, et al. Long-term outcomes after percutaneous coronary intervention for chronic total occlusion (from the CREDO-Kyoto registry cohort-2). Am J Cardiol 2013; 112: 767-74.

33. Patel VG, Brayton KM, Tamayo A, et al. Angiographic success and procedural complications in patients undergoing percutaneous coronary chronic total occlusion interventions: a weighted meta-analysis of 18,061 patients from 65 studies. JACC Cardiovasc Interv 2013; 6: 128-36.

34. Mehran R, Claessen BE, Godino C, et al. Long-term outcome of percutaneous coronary intervention for chronic total occlusions. JACC Cardiovasc Interv 2011; 4: 952-61.

35. Patel VG, Michael TT, Mogabgab O, et al. Clinical, angiographic, and procedural predictors of periprocedural complications during chronic total occlusion percutaneous coronary intervention. J Invasive Cardiol 2014; 26: 100-5. 